\title{
Activating AKT to inhibit JNK by troxerutin antagonizes radiation-induced
}

\section{PTEN activation}

\section{ABSTRACT}

Radiotherapy is one of the most effective non-surgical treatments for many tumors. However, radiation damage remains a major negative consequence of radiotherapy. At present, radio-protective effect of troxerutin has been confimed, but the mechanism of this radioprotection has not been elucidated. Here, this study showed that troxerutin protected thymus tissue of irradiated mice, and its radio-protective effect on thymocytes was significant in the range of $0.625-10 \mu \mathrm{g} / \mathrm{ml}$. Troxerutin significantly inhibited apoptosis of irradiated thymocytes at the concentration of $10 \mu \mathrm{g} / \mathrm{ml}$. Computer-aided drug design was used to investigate potential candidate targets for troxerutin, and an excellent correlation was identified between troxerutin and AKT (Pharm mapper and KEGG signal pathway). Troxerutin inhibited the activation of PTEN to stimulate AKT, which in turn prevented the activation of JNK to protect cells. Our results showed that troxerutin enhanced radioprotection at least partially by activating AKT to inhibit the activation of JNK.

Key Words: Troxerutin, Thymus cell, AKT, PTEN, JNK

\section{Introduction}

According to WHO (the World Health Organization) estimates, there are 900 million new cases of cancer patients around the world each year. 50-70\% of patients with tumors need to receive radiation therapy. However, side effects of the radiation 
treatment seriously interfere with the life quality of patients and sometimes cause patients to discontinue treatment because of radiation injury (Henriquez-Hernandez et al., 2012; Ospina et al., 2015; Bernier, 2009). A major obstacle that needs overcome is to minimize radiation damage of normal tissue and thus improve the efficacy of radiotherapy. Therefore, it is very important to explore the targets and mechanism of radiation protection to design more appropriate strategies and effective target drugs for the prevention and treatment of radiation injury.

The flavanoid derivative troxerutin $\{2-[3,4$-bis (2-hydroxyethoxy) phenyl]-3[(6deoxy- $\alpha$-L-manno-pyranosyl)- $\beta$ (-D-glucopyranosyl)-oxy]-5-hydroxy-7-

(2hydroxyethoxy)-4H-1-benzo-pyran-4-one $\}$ has been used therapeutically to treat multiple disorders, including chronic venous insufficiency (CVI), varicosity, and capillary fragility. Troxerutin has anti-erythrocytic, antithrombotic, fibrinolytic and edema-protective activities (Vanscheidt et al., 2002; Incandela et al., 1996). One study showed that troxerutin protected against ultraviolet $\mathrm{B}$ radiation injury through the regulation of miRNAs (Lee et al., 2014; Cha et al., 2014) and prevented gamma-ray radiation damage by protecting the integrity of DNA (Maurya et al.,2005). However, the target genes of miRNAs and target molecules of troxerutin in radiation damage have not been corroborated. The objective of this study is to determine the molecular mechanism of radiation protection of troxerutin.

Three-dimensional structure of troxerutin was imported into the Pharm Mapper database to be processed by reverse docking. This computational analysis produced many potential targets. UniProt database and Kyoto Encyclopedia of genes and 
genomes (KEGG) database (http://www.genome.jp/kegg/) were used to analyze the function and pathway of the possible targets. In this way, AKT and JNK were identified as potentially important targets for radioprotection of troxerutin. Next, the target of AKT was selected as the key target of this study. Radiation-sensitive signaling pathway associated with AKT was identified as PTEN/AKT/JNK. As thymus is extremely reactive to ionizing radiation, it was used to investigate the molecular mechanism of radiation protection of troxerutin in this study.

\section{Materials and methods}

\subsection{Materials}

Male KM mice (4-6 weeks old, weighing 18-22 g) were purchased from the Experimental Animal Center of Xinxiang Medical University. Animals were housed at 10 per cage with ad libitum access to water and food pellets. Thymus cells were cultured in suspension in RPMI-1640 medium containing $10 \%$ fetal bovine serum, $100 \mathrm{U} / \mathrm{ml}$ penicillin, and $100 \mathrm{U} / \mathrm{ml}$ streptomycin at $37^{\circ} \mathrm{C}$ in a humidified atmosphere of $5 \% \mathrm{CO} 2$. Tissue Freezing Medium of Thermo Richard-Allan NEG-50 was purchased from Thermo Fisher Scientific Inc. (Waltham, MA USA). Cell counting kit-8 (CCK-8) was manufactured by Dojindo Laboratories (Kumamoto, Japan). Apoptosis kit was obtained from Bao-Sai Biotechnology Co., Ltd, Beijing, China. RPMI-1640 and fetal calf serum were purchased from Gibco BRL (Gaithersburg, USA). Antibodies for rabbit anti-pAKT S473, anti-p-JNK1/2/3, anti-PTEN, anti-p-PTEN were purchased from Abcam (Cambridge UK). Second antibodies were goat anti-rabbit IgG-Cy3 and IgG-FITC from 
Bi-Yun-Tian Biotechnology Co., Ltd, Shanghai, China. LY294002 was purchased from Selleck Chemicals (Houston, USA).

\subsection{Irradiation}

Cells were irradiated at room temperature with an X-ray at a dose of 6 Gy. The animals were restrained in holders and exposed to 6 Gy total-body X-ray radiation.

\subsection{Design of experiment (Tab.1)}

\subsubsection{Observation of thymus appearance shape}

On the 3 rd day after irradiation, mice were killed to obtain the thymus, and the morphology was observed by the use of a stereo microscope. Thymus index is calculated as the relative weight (Thymus index $=$ thymus weight $* 1000 /$ body weight).

\subsubsection{Morphological and histological analyses}

Excised thymuses were fixed in $4 \%$ paraformaldehyde solution, dehydrated in serial alcohol solutions, embedded in paraffin, cut into $5 \mu \mathrm{m}$ slices in thickness, stained with HE (Hematoxylin-eosin) staining, and examined under a light microscope.

\subsubsection{Apoptosis of thymus tissue measured by Hoechst}

On the $3^{\text {rd }}$ day after irradiation, thymuses were obtained and fixed in $4 \%$ paraformaldehyde at $4{ }^{\circ} \mathrm{C}$ for $24 \mathrm{~h}$. Fixed thymuses were sequentially put into $20 \%$ and $30 \%$ sucrose solution to be dehydrated. Next, the thymuses were embedded in frozen embedding agent and were cut into $4 \mu \mathrm{m}$ slices by a frozen section machine. These tissue slices were stained with Hoechst 333258 and examined under a fluorescence microscope.

\subsubsection{Detection of cell toxicity and cell viability}



in 96-well plates containing $100 \mu \mathrm{l} /$ well of drug at a final concentration of $\quad 320,160$, $80,40,20,10,5$ and $2.5 \mu \mathrm{g} / \mathrm{ml}$ (referred to as the drug groups). CCK-8 solution $10 \mu \mathrm{l}$ was added to each well at $48 \mathrm{~h}$ after drug intervention. The absorbance of each well at $490 \mathrm{~nm}$ was determined after a further $4 \mathrm{~h}$, using a multifunctional microplate reader. $100 \mu 1 /$ well of thymocytes $\left(1 \times 10^{6}\right.$ cells/ml $)$ in logarithmic growth phase were seeded in 96-well plates and were divided into normal group, radiation group, and drug groups. 
analyzed by flow cytometry (FCM) to detect apoptosis.

In addition, the Hoechst staining method was applied to the detection of cell apoptosis. Thymocytes were harvested and were uniformly coated onto microscope slides to prepare for Hoechst 333258 staining. The microscope slides stained by Hoechst 333258 were examined under a fluorescence microscope.

\subsubsection{Immunoblot analysis of AKT, PTEN, JNK in vitro}

Thymocytes $\left(1 \times 10^{6}\right.$ cells $\left./ \mathrm{ml}\right)$ were treated with troxerutin at a final concentration of $5 \mu \mathrm{g} / \mathrm{ml}$ and $10 \mu \mathrm{g} / \mathrm{ml}$. After interacting with each other for $2 \mathrm{~h}$, cells were irradiated at a dose of 6 Gy. The inhibitor LY294002 of PI3K/AKT was added at $24 \mathrm{~h}$ before radiation with the final concentration of $50 \mu \mathrm{M}$. Cells were collected at $45 \mathrm{~min}$ and $2 \mathrm{~h}$ after irradiation respectively, to which the mixed lysate (RIPA: PMSF 99:1, concentration of PMSF 1mM) was added at a volume according to the amount of cells. The mixed liquid induced lysis completely and then was centrifuged $\left(4{ }^{\circ} \mathrm{C}, 10000 \mathrm{~g}, 5 \mathrm{~min}\right)$ to obtain the supernatant, which was preserved at $-80^{\circ} \mathrm{C}$. The protein concentration was measured by BCA method. The samples obtained at $45 \mathrm{~min}$ after irradiation were then used to measure levels of AKT and PTEN. The samples got at $2 \mathrm{~h}$ after irradiation were used to measure levels of JNK.

Total cellular protein was analyzed by western blotting. The blots were incubated with primary antibodies of AKT, PTEN, and JNK overnight at $4^{\circ} \mathrm{C}$ with suitable concentration recommended by manufacturer. Further incubation was performed with HRPconjugated secondary antibody. The signal was detected using ECL reagents. 
microscopy

treatment groups after adapting to the environment. All drugs were administered orally.

Mice in the normal and irradiation groups were treated with distilled water, and mice in the treatment groups were given troxerutin at a dose of $5 \mathrm{mg} / \mathrm{kg}$ or $10 \mathrm{mg} / \mathrm{kg}$. After 4 days, mice were irradiated at a dose of 6 Gy. The thymus tissue was frozen and sliced as described above. These sections were permeabilized by $0.1 \%$ Triton for 20 min and were washed three times with $0.01 \mathrm{M}$ PBS for $5 \mathrm{~min}$, followed by closing in $10 \%$ goat serum for $1 \mathrm{~h}$. The slices were incubated with the corresponding primary antibodies of AKT/JNK and secondary antibody. The DAPI solution was added and incubated at room temperature for $10 \mathrm{~min}$ in darkness, followed by addition of anti-fluorescence quenching in the absence of light. The signal was detected by laser scanning confocal microscopy.

\subsection{Statistical analysis}

Data was expressed as mean \pm standard deviation (S.D.). The data was analyzed using analysis of variance (ANOVA) on SPSS/PC* (statistical package for social sciences, personal computer) and Image $\mathbf{J}$ software. The group means were compared by Duncan's Multiple Range Test (DMRT). The means of the treated groups were compared with those of the radiation-alone. A value of $P<0.05$ or $P<0.01$ was considered to be statistically significant. Relative fluorescence intensity was determined by Image $\mathbf{J}$ software.

\section{Results}




\subsection{Troxerutin improved the pathological changes of thymus and reduced} apoptosis of thymus.

The radiation-induced model of thymus tissue was successfully established, and relative weight and pathological changes of the thymus were studied. As shown in Fig. $2 \mathrm{~A}$, the relative weight of the radiation group was significantly reduced, but it was significantly increased in troxerutin group. Fig. 2B showed that in the normal group, the cortex and medulla of thymus were clearly defined and exhibited proper proportion. The morphology of thymocytes appeared very regular, and the nuclear chromatin distribution appeared similarly uniform. The structure of the cortex and medulla of the radiation group was not clear at $3 \mathrm{~d}$ (days) after irradiation, and the number of thymocytes was extremely reduced, leaving a small number of them. The thymus tissue appeared close to normal in the $5 \mathrm{mg} / \mathrm{kg}$ and $10 \mathrm{mg} / \mathrm{kg}$ treatment groups as a large number of lymphocytes were recovered, and the cortex and medulla structure was clear. Further, Hoechst staining was used to observe the effect of troxerutin on the apoptosis of thymus tissue. Fig. 2C shows that the living cell nucleus exhibited homogeneous blue fluorescence, and apoptotic bodies appeared in the late apoptotic cells in thymus tissue as evidenced by Hoechst staining. Addition of troxerutin at either $5 \mathrm{mg} / \mathrm{kg}$ or $10 \mathrm{mg} / \mathrm{kg}$ significantly inhibited the formation of apoptotic bodies in thymus tissue. 
In order to determine the best dose of troxerutin, the toxicity of troxerutin for thymocytes was determined. The viability at $48 \mathrm{~h}$ after drug intervention was shown in

Fig. 3 A. Troxerutin showed no significant cytotoxicity in the range of $2.5-20 \mu \mathrm{g} / \mathrm{ml}$.

To determine whether troxerutin could enhance radioprotection, thymocytes were exposed to radiation with $6 \mathrm{~Gy}$ at a dose rate of $227.7 \mathrm{cGy} / \mathrm{min}$. Cells were treated with troxerutin for $2 \mathrm{~h}$ before radiation. As shown in Fig. $3 \mathrm{~B}$, at $6 \mathrm{~h}$ after radiation, there was obvious reduction of cell viability and an increase in apoptosis. In contrast, treatment with troxerutin before radiation significantly enhanced thymocytes viability and reduced apoptosis. The viability of the irradiated cells gradually increased with increasing concentrations of troxerutin in the range of $0.625-10 \mu \mathrm{g} / \mathrm{ml}$. The viability was highest at $10 \mu \mathrm{g} / \mathrm{ml}$. As shown in Fig. $3 \mathrm{C}$, troxerutin significantly reduced cell apoptosis compared with the irradiation group, indicating that troxerutin provided an anti-apoptosis effect.

\subsection{Troxerutin reduced cell apoptosis partially by inhibition of PTEN and} activation of AKT

214 thymocytes were treated with troxerutin and the activated forms of PTEN and AKT

215 were examined after radiation treatment. As shown in Fig. 4 A, the apoptosis induced

216 by radiation was higher than normal, but was reduced when troxerutin treatment was

217 provided before radiation. The inhibitor of AKT (LY294002 $50 \mu \mathrm{M})$ significantly

218 reduced the anti-apoptosis effect of troxerutin at $6 \mathrm{~h}$ after irradiation, suggesting that

219 troxerutin could activate Akt to inhibit apoptosis. Since PTEN was shown previously 
to cause dephosphorylation of PIP3 to produce PIP2, reverse to the activating of AKT, the protein expression of PTEN was also determined. As shown in Fig. 4 B and C, the protein expression of PTEN was up-regulated after radiation, and the phosphorylation of PTEN and AKT was inhibited in thymocytes. Troxerutin at $5 \mu \mathrm{g} / \mathrm{ml}$ or $10 \mu \mathrm{g} / \mathrm{ml}$ acted to down-regulate PTEN and improve the expression of p-PTEN and p-AKT. LY294002 $(50 \mu \mathrm{M})$ was added to thymocytes at $24 \mathrm{~h}$ before irradiation, and the expression of p-AKT was almost completely inhibited at 45 min after irradiation.

\subsection{Troxerutin inhibited JNK by activating AKT}

In order to determine the mechanism of anti-apoptosis by AKT in thymocytes, the downstream molecule of JNK was further monitored at $2 \mathrm{~h}$ after radiation. As shown in Fig. $5 \mathrm{~A}$, the expression of p-JNK protein was significantly higher after accession of AKT siRNA compared with troxerutin alone. As shown in Fig. 5 B and C, the expression of p-JNK protein was significantly higher after radiation compared with the normal group, and it was considerably decreased in cells that received troxerutin compared with the cells that received radiation alone. LY294002 (50 $\mu \mathrm{M})$ was added to thymocytes at $24 \mathrm{~h}$ before irradiation, and the expression of $\mathrm{p}$-JNK significantly increased at $2 \mathrm{~h}$ after irradiation. These results suggested that troxerutin contributed to radioprotection at least partially by antagonizing the radiation-induced activation of JNK.

\section{Discussion}

This study showed that troxerutin could upregulate p-AKT expression or activation to increase radioprotection of thymocytes. The findings provided that radiation may 
increase PTEN to decrease phosphorylation of PTEN and AKT, which further activate JNK. Troxerutin could down-regulate and inactivate PTEN to activate AKT, inhibiting phosphorylation of JNK.

The phosphorylation of AKT at S473 or T308 is required for the activated form of AKT (Cicenas et al., 2008). AKT promotes cell proliferation, inhibits apoptosis, and enhances cell invasion, thereby regulating various cellular functions (Zhang et al., 2007). The pathway of PI3K/AKT was activated in some cancer cells (Chen et al., 2015; Simpson et al., 2015; Ettl et al., 2015), which improved the cell resistance to radiation damage and reduced radiation sensitivity. The PI3K/AKT signaling pathway also plays a crucial role in the radioprotection of normal cells. When normal cells were exposed to radiation, the PI3K / AKT signaling pathway was inhibited and drug intervention was able to further activate PI3K / AKT to inhibit the cell apoptosis induced by radiation (Yang et al., 2014).

Phosphatase and tensin homolog deleted on chromosome ten (PTEN) is an important tumor-suppressor, and is a key negative regulator of the PI3K/AKT pathway by dephosphorylating phosphatidylinositol-3,4,5-trisphosphate (PIP3). This dephosphorylation will cause PIP3 to be dephosphorylated to produce PIP2 (Meng et al., 2015;Vazquez et al., 2000; Keniry et al., 2008; Bao et al., 2013). Membrane-bound PTEN is the activated form of PTEN (Vazquez et al., 2006; Denning et al., 2007; Walker et al., 2004). However, phosphorylation of PTEN at S380, T382, T383, and S385 decreases PTEN membrane translocation to deactivate PTEN (Denning et al., 2007). Therefore, agents that inhibit PTEN could activate AKT's function in 
radioprotection. Decreased expression of PTEN was reported to induce radio-resistance through promotion of cell proliferation and inhibition of cell apoptosis in non-small cell lung cancer and nasopharyngeal carcinoma (Jung et al., 2010; Qu et al., 2012). Directly restoring PTEN function has previously been reported as a valuable approach to achieve radio-sensitization in vitro (Zhang et al.,2010). However, whether PTEN participates in radiation-induced apoptosis in normal cells is not yet known. In this study, radiation increased PTEN to decrease the phosphorylation of PTEN, and troxerutin downregulated and inactivated PTEN.

Activation of AKT could result from the inactivation of PTEN in radioprotection. Interleukin-11 protected intestines in mice against neutron radiation injury via PI3K/AKT pathway (Yang et al., 2014) and polypeptides from the scallop protected thymus lymphocytes by activating the PI3K/AKT signaling pathway (Chen et al., 2008). Our finding was consistent with previous findings, but contradicted the reported regulatory behavior of AKT in cancer cells. For example, radiation induced AKT phosphorylation at T308 and S473 in two types of cancer cells. COX-2 inhibitors activated PTEN to antagonize radiation-induced PTEN inactivation and AKT activation, contributing to radio-sensitization (Zhen et al., 2015).

The downstream effect of AKT activation is closely related to the inhibition of the apoptotic pathway. Studies have shown that ASK1 is an oxygen sensitive MAP-KKK that is able to activate JNK to induce apoptosis (Wang et al.,2007). AKT can negatively regulate the activity of ASK1, causing the JNK signal to be reduced (Wang et al.,2012; Luyendyk et al.,2007). Therefore, the regulation of the AKT-JNK signaling pathway 
played a role in the mechanism, by which troxerutin acted to improve radiation resistance (Fig.1). Here, this study was designed to investigate the radio-protective effect of troxerutin and its anti-apoptotic mechanism via the PTEN/ AKT /JNK pathway in vitro and in vivo.

Studies showed that lethal doses of gamma radiation (GR) induced JNK activities during early apoptosis in Jurkat T-cells (Chen et al., 1996). Polypeptides from the scallop protected thymus lymphocytes by activating the PI3K/AKT signaling pathway to inhibit activation of JNK (Chen et al., 2008). Our study showed the amount of phosphorylated JNK1/2/3 increased after radiation and troxerutin significantly reduced the amount of activated JNK1/2/3.

In conclusion, this study showed that troxerutin inactivated PTEN to activate AKT, inhibiting phosphorylation of JNK, leading to enhanced radioprotection.

\section{Conflict of interest}

None declared.

\section{Acknowledgements}

This work was supported by the Department of Science and Technology Research Project of Henan Province in China (142102310302) and the National Science Foundation of China (U1504824). We sincerely thank Dr. Cheng BinFeng for the excellent computer-aided drug design assistance and guidance.

\section{References}

Bao, L., Yan, Y., Xu, C., 2013. MicroRNA-21 suppresses PTEN and hSulf-1 expression and promotes hepatocellular carcinoma progression through AKT/ERK pathways. Cancer Lett, 337(2), 226-236. 
Bernier, J., 2009. Current state-of-the-art for concurrent chemoradiation. Semin. Radiat. Oncol. 19(1), 3-10.

Cha, H.J., Lee, K.S., Lee, G.T., 2014. Altered miRNA expression profiles are involved in the protective effects of troxerutin against ultraviolet $\mathrm{B}$ radiation in normal human dermal fibroblasts. Int. J. Mol. Med. 33(4), 957-63.

Chen, Y.H., Wei, M.F., Wang, C.W., 2015. Dual Phosphoinositide 3-kinase/mammalian target of rapamycin inhibitor is an effective radiosensitizer for colorectal cancer. Cancer Lett. 357(2), 582590.

Cicenas, J., 2008. The potential role of Akt phosphorylation in human cancers, Int. J. Biol. Markers. 23(1),1-9.

Chen, H.Y., Zhou, Y.B., Wang, C.B., Yu, W.G., Lan, X.M., 2008. Effects of polypeptides from scallop on PI3K/Akt and ASK1-JNK signaling pathway in thymus lymphocytes of mice irradiated with UVB. Chin. J. marine drugs. 27(1), 13-17.

Chen, Y.R., Meyer, C.F., 1996. Tan TH. Persistent activation of c-Jun N-terminal kinase 1 (JNK1) in gamma radiation-induced apoptosis. J. Biol. Chem. 271(2), 631-634.

Denning, G., Jean-Joseph, B., Prince, C., Durden, D.L., Vogt, P.K., 2007. A short N-terminal sequence of PTEN controls cytoplasmic localization and is required for suppression of cell growth. Oncogene. 26(27), 3930-3940.

Ettl, T., Viale-Bouroncle, S., Hautmann, M.G., 2015. AKT and MET signalling mediates antiapoptotic radioresistance in head neck cancer cell lines. Oral. Oncol. 51(2),158-163.

Henriquez-Hernandez, L.A., Bordon, E., Pinar, B., 2012. Prediction of normal tissue toxicity as part of the individualized treatment with radiotherapy in oncology patients. Surg. Oncol. 21(3), 201206.

Incandela, L, De Sanctis, MT, Cesarone, MR, Laurora, G, Belcaro, G, Taccoen, A. 1996. Efficacy of troxerutin in patients with chronic venous insufficiency: a double-blind, placebo-controlled study. Adv. Ther. 13,161-166.

Jung, I.L., Kang, H.J., Kim, K.C., Kim, I.G., 2010. PTEN/pAkt/p53 signaling pathway correlates with the radioresponse of non-small cell lung cancer. Int. J. Mol. Med. 5(4), 517-523.

Keniry, M., Parsons, R., 2008. The role of PTEN signaling perturbations in cancer and in targeted therapy. Oncogene. 27(41), 5477-5485. 
Lee, K.S., Cha, H.J., Lee, G.T., 2014. Troxerutin induces protective effects against ultraviolet B radiation through the alteration of microRNA expression in human $\mathrm{HaCaT}$ keratinocyte cells. Int. J. Mol. Med. 33(4), 934-42.

Luyendyk, J.P., Piper, J.D., Tencati, M., 2007. A novel class of antioxidants inhibit LPS induction of tissue factor by selective inhibition of the activation of ASK1 and MAP kinases. Arterioscler. Thromb. Vasc. Biol. 27(8), 1857-1863.

Maurya, D.K., Balakrishnan, S., Salvi, V.P., 2005. Protection of cellular DNA from gammaradiation-induced damages and enhancement in DNA repair by troxerutin. Mol. Cell Biochem. 280(1-2), 57-68.

Meng, Z., Gan, Y.H., 2015. Activating PTEN by COX-2 inhibitors antagonizes radiation-induced AKT activation contributing to radiosensitization. Biochem. Biophys. Res. Commun. 460(2), 198-204.

Ospina, J.D., Fargeas, A., Drean, G., 2015. Recent advancements in toxicity prediction following prostate cancer radiotherapy. Conf. Proc. IEEE Eng. Med. Biol. Soc. 8, 5231-5234.

Qu, C., Liang, Z., Huang, J., Zhao, R., Su, C., Wang, S., 2012. MiR-205 determines the radioresistance of human nasopharyngeal carcinoma by directly targeting PTEN. Cell Cycle. 11(4),785-796

Simpson, D.R., Mell, L.K., Cohen, E.E., 2015. Targeting the PI3K/AKT/mTOR pathway in squamous cell carcinoma of the head and neck. Oral. Oncol. 51(4), 291-298

Vanscheidt, W, Rabe, E, Naser-Hijazi, B, Ramelet, AA, Partsch, H, Diehm, C. 2002. The efficacy and safety of a coumarin-/ troxerutin-combination (SB-LOT) in patients with chronic venous insufficiency: a double blind placebo-controlled randomized study. Vasa. 31,185-190.

Vazquez, B.F., Sellers, W.R., 2000. The PTEN tumor suppressor protein: an antagonist of phosphoinositide 3-kinase signaling. Biochim. Biophys. Acta. 1470(1), M21-35.

Vazquez, F., Matsuoka, S., Sellers, W.R., Yanagida, T., Ueda, M., Devreotes, P.N., 2006. Tumor suppressor PTEN acts through dynamic interaction with the plasma membrane. Proc. Natl. Acad. Sci. U. S. A. 103(10), 3633-3638.

Walker, S.M., Leslie, N.R., Perera, N.M., Batty, I.H., Downes, C.P., 2004.The tumour suppressor function of PTEN requires an N-terminal lipid-binding motif.

Biochem. J. 379(Pt 2),301-307 
Wang, Q., Zhang, Q.G., Wu, D.N., 2007. Neuroprotection of selenite against ischemic brain injury through negatively regulating early activation of ASK1/JNK cascade via activation of PI3K/AKT pathway. Acta. Pharmacol. Sin. 28(1), 19-27.

Wang, X., Chen, W.R., Xing, D., 2012. A pathway from JNK through decreased ERK and Akt activities for FOXO3a nuclear translocation in response to UV irradiation. J. Cell Physiol. 227(3), $1168-1178$.

Yang, L., Wang, R., Gao, Y., 2014. The protective role of interleukin-11 against neutron radiation injury in mouse intestines via MEK/ERK and PI3K/Akt dependent pathways. Dig. Di. Sci. 59(7), $1406-1414$.

Zhang, C., Kang, C., Wang, P., Cao, Y., Lv, Z., Yu, S., 2011. MicroRNA-221 and -222 regulate radiation sensitivity by targeting the PTEN pathway. Int. J. Radiat. Oncol. Biol. Phys. 80(1), 240248.

Zhang, X., Jin, B., Huang, C., 2007. The PI3K/Akt pathway and its downstream transcriptional factors as targets for chemoprevention. Curr. Cancer Drug Targets. 7(4), 305-316.

Zhen, M., Gan, Y.H., 2015. Activating PTEN by COX-2 inhibitors antagonizes radiation-induced AKT activation contributing to radiosensitization. Biochem. Biophys. Res. Commun. 460(2), 198-204.

(1)

(1)

$$
198-204 .
$$




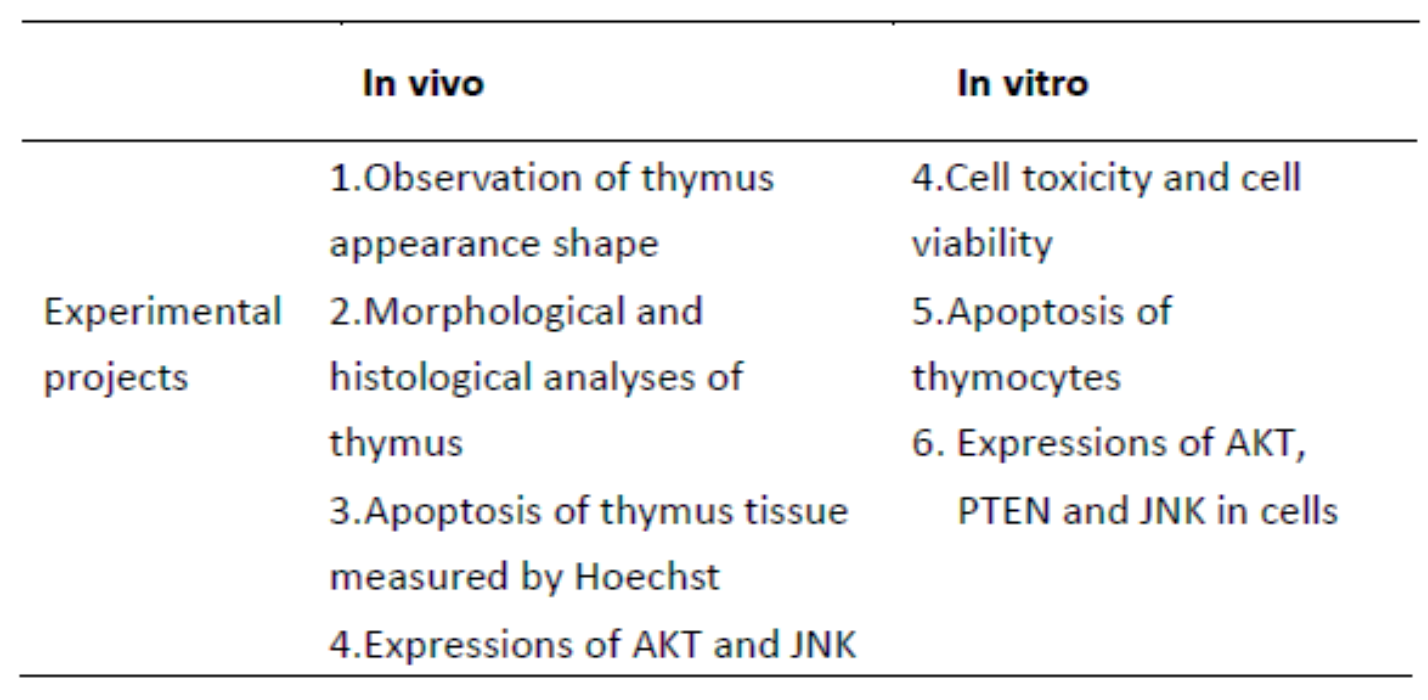

Figure legends

Fig.1 Molecular mechanism of troxerutin on radiation damage via AKT

Fig. 2 Protective effect of troxerutin (TRT) on the thymus of mice irradiated at a dose of $6 \mathrm{~Gy}(\mathrm{n}=5)$. (A) Effect of troxerutin on the relative weight of thymus in irradiated mice. (*, $\mathrm{P}<0.01$ compared with control; \#, $\mathrm{P}<0.01$ compared with irradiation alone). (B) Effect of troxerutin on the pathological changes of thymus in irradiated mice. ${ }^{*}, \mathrm{P}<0.01$ compared with control; \#, $\mathrm{P}<0.01$ compared with irradiation alone). (C) Effect of troxerutin on apoptosis of thymus tissue in irradiated mice. (*, $\mathrm{P}<0.01$ compared with control; \#, $\mathrm{P}<0.01$ compared with irradiation alone).

Fig.3 Protective effect of troxerutin on the thymocytes of mice irradiated by a dose of 407 6 Gy $(n=5)$. (A) Viabilities of thymocytes treated with troxerutin. Troxerutin showed no significant cytotoxicity in the range of $2.5-20 \mu \mathrm{g} / \mathrm{ml}$. (*, $\mathrm{P}<0.01$ compared with control). (B) Viabilities of thymocytes treated with troxerutin at different concentrations. (*, $\mathrm{P}<0.01$ compared with control; \#\#, $\mathrm{P}<0.01$ compared with irradiation alone). (C) Hoechst staining was performed to detect the effect of 
troxerutin on the apoptosis of thymocytes with radiation injury. (*, P $<0.01$ compared with control; \#, P $<0.01$ compared with irradiation alone).

414 Fig.4 Troxerutin reduced cell apoptosis partially by inhibiting PTEN and activating 415 AKT $(n=5)$. (A) The effect of troxerutin and AKT inhibitor on apoptosis of 416 thymocytes measured by flow cytometry. The inhibitor of AKT (LY294002) 417 significantly reduced the anti-apoptosis effect of troxerutin, suggesting that 418 troxerutin may activate AKT to inhibit apoptosis $(*, \mathrm{P}<0.01$ compared with control ; $419 * *, \mathrm{P}<0.01$ compared with irradiation alone; \#, $\mathrm{P}<0.01$ compared with the 420 corresponding group without inhibitor). (B) Effect of troxerutin on the expression of 421 p-AKT in thymocytes after irradiation measured by Western blot and laser scanning 422 confocal microscopy. Expressions of p-AKT were improved by Troxerutin at $5 \mu \mathrm{g} / \mathrm{ml}$ 423 and $10 \mu \mathrm{g} / \mathrm{ml}$, and the inhibitor of AKT (LY294002) significantly inhibited the effect 424 of troxerutin $\left(^{*}, \mathrm{P}<0.01\right.$ compared with control; **, $\mathrm{P}<0.01$ compared with 425 irradiation alone) (C) Effect of troxerutin on the expressions of p-PTEN and PTEN 426 in thymocytes after irradiation. Troxerutin of $5 \mu \mathrm{g} / \mathrm{ml}$ and $10 \mu \mathrm{g} / \mathrm{ml}$ could 427 downregulate PTEN, and improve the expression of p-PTEN (*, P $<0.01$ compared 428 with control; **, $\mathrm{P}<0.01$ compared with irradiation alone).

429 Fig.5 Troxerutin inhibited JNK by activation of AKT $(n=5)$. Effect of troxerutin on the 430 expressions of p-JNK in thymocytes after AKT siRNA accession (A) $\left(^{*}, \mathrm{P}<0.01\right.$ 431 compared with control). Effect of troxerutin on the expressions of p-JNK in 432 thymocytes after irradiation as measured by Western blot (B) and laser scanning confocal microscopy $(\mathrm{C}) \quad(*, \mathrm{P}<0.01$ compared with control ; **, $\mathrm{P}<0.05$ 
Fig.1

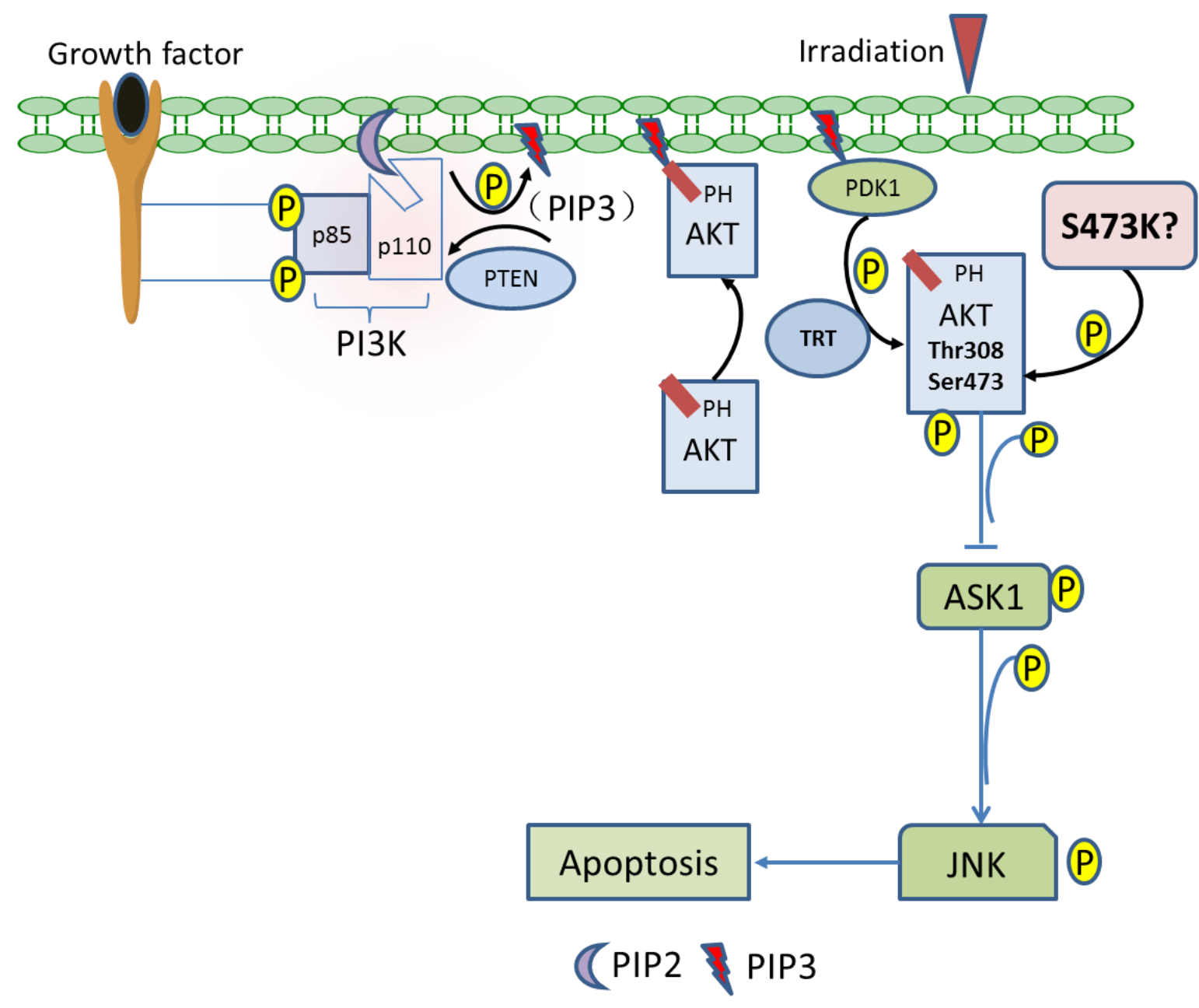


Fig. 2
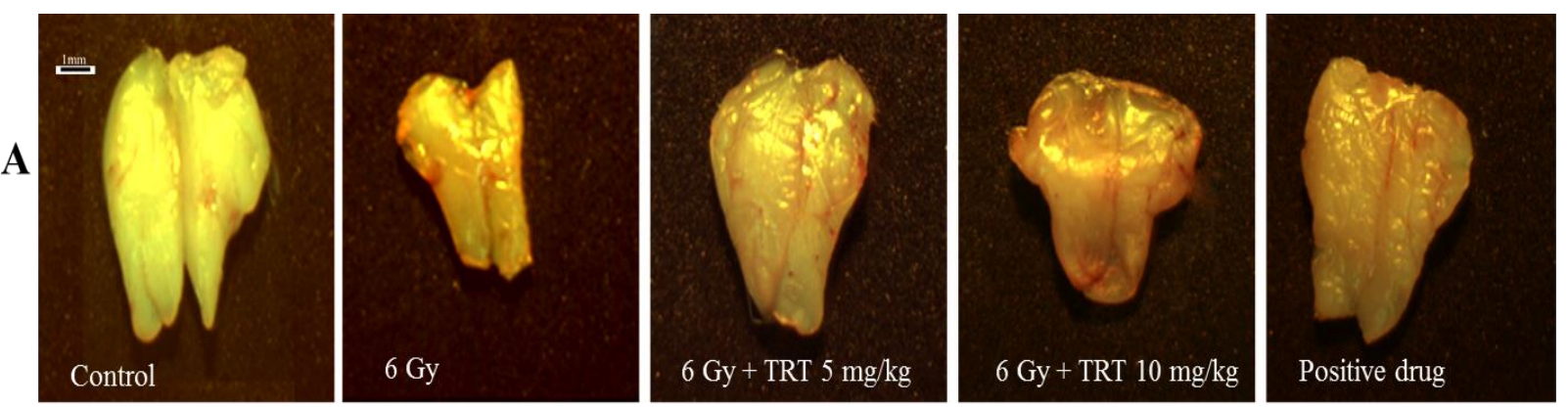

447
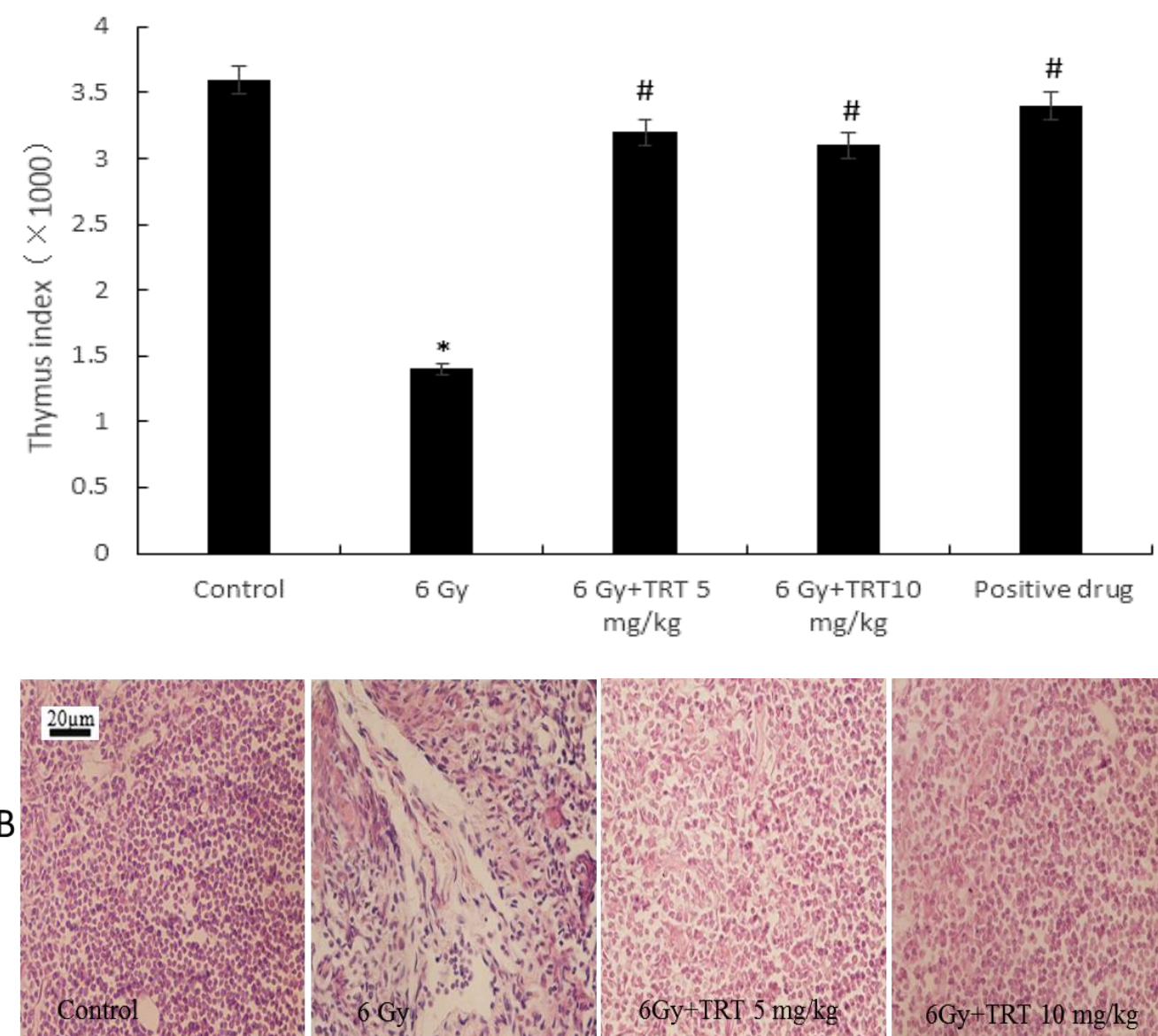

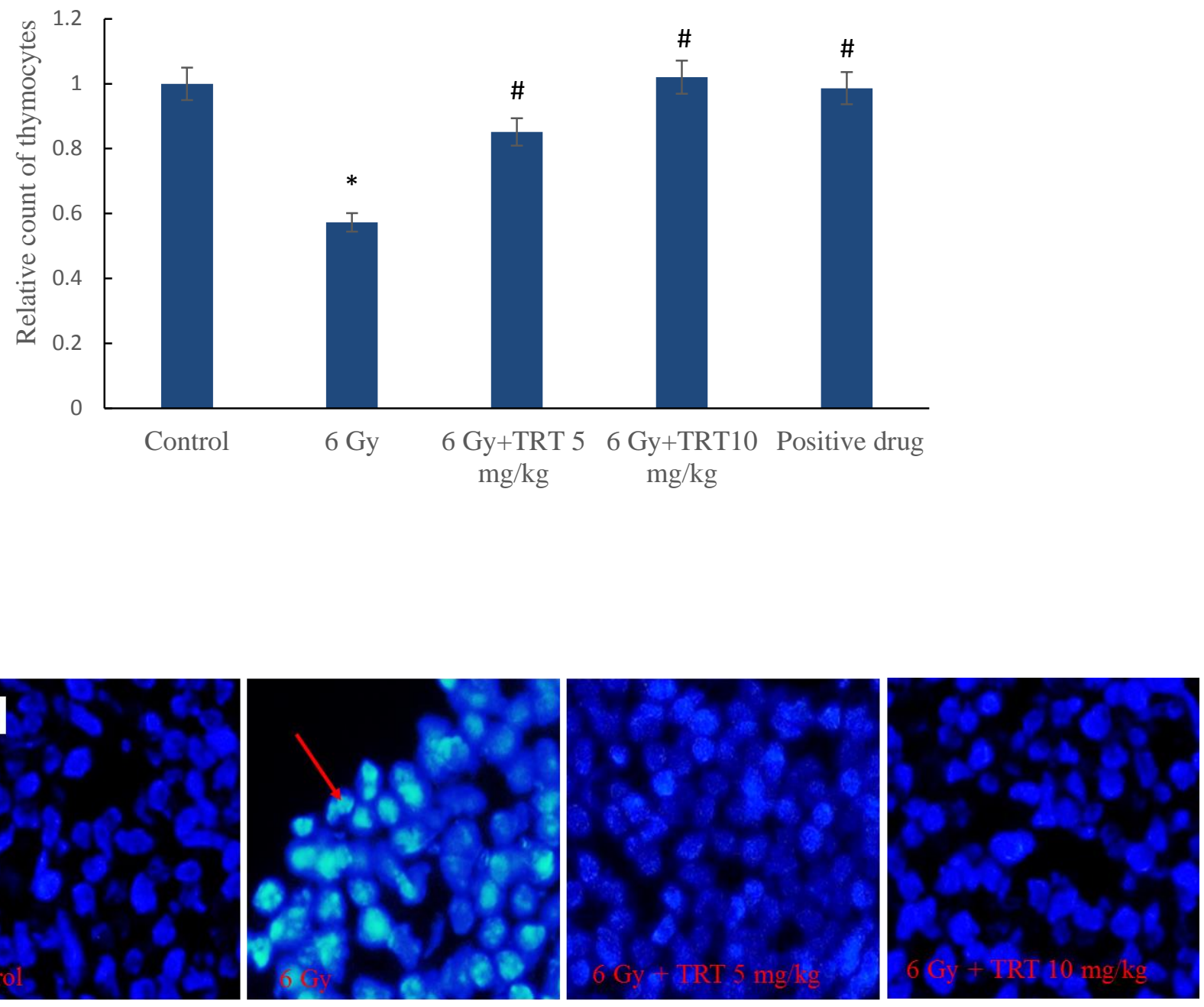

459

460

461

462

463

464

C $10 u m$

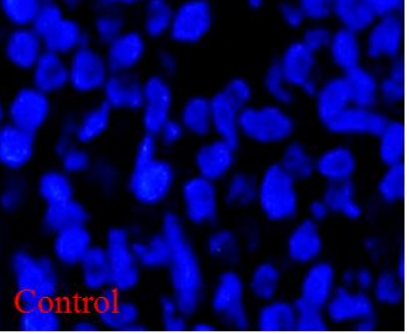


Fig.3

470

471

472

473

474

475

476

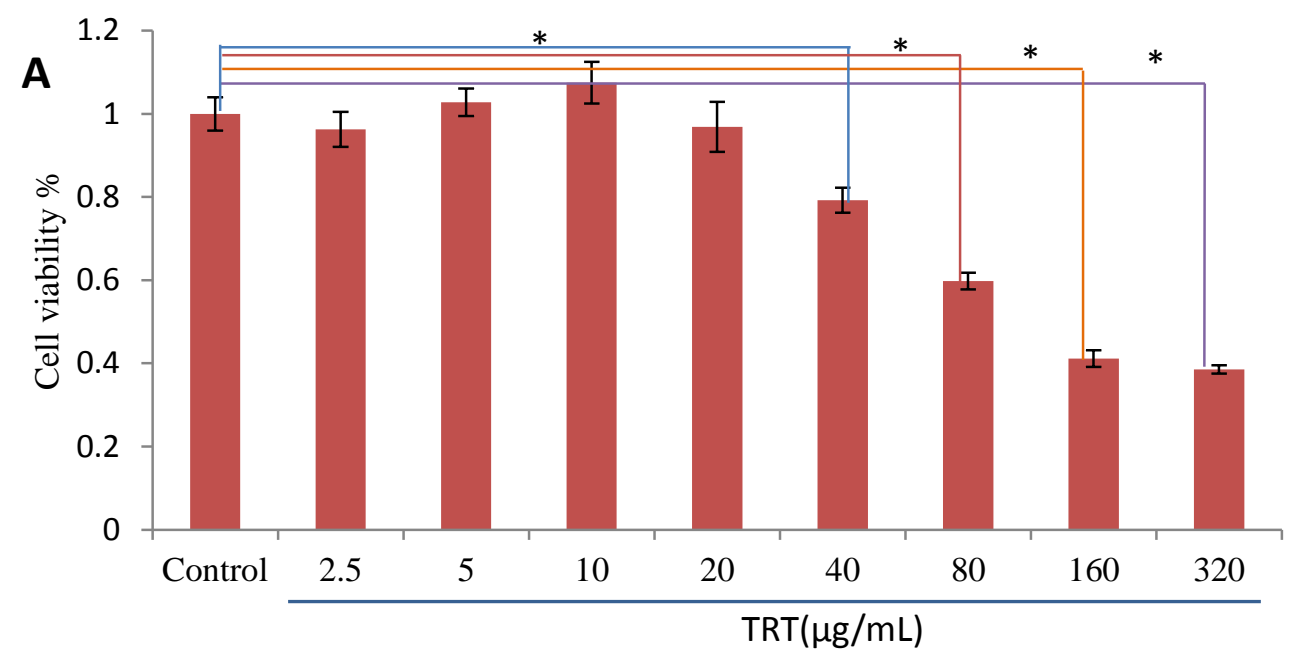

477

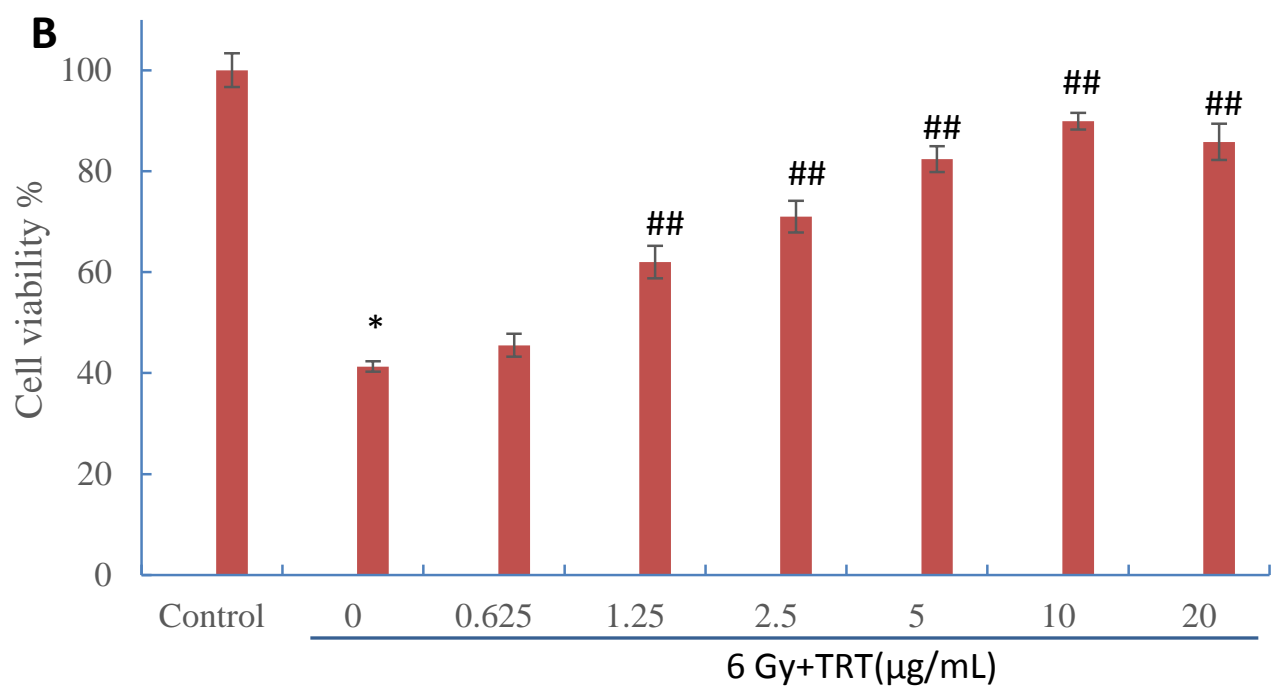

478

479

C

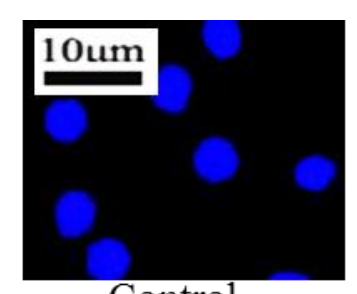

Control

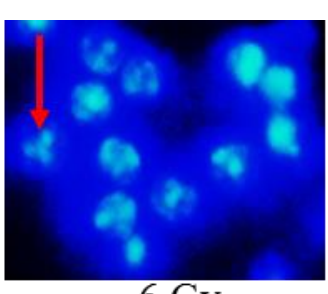

6 Gy
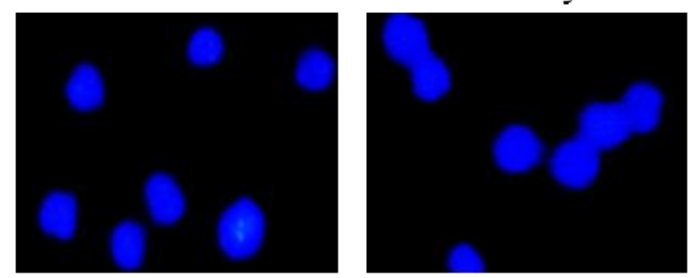

$6 \mathrm{~Gy}+\mathrm{TRT} 5 \mu \mathrm{g} / \mathrm{mL} 6 \mathrm{~Gy}+\mathrm{TRT} 10 \mu \mathrm{g} / \mathrm{mL}$ 
480

481

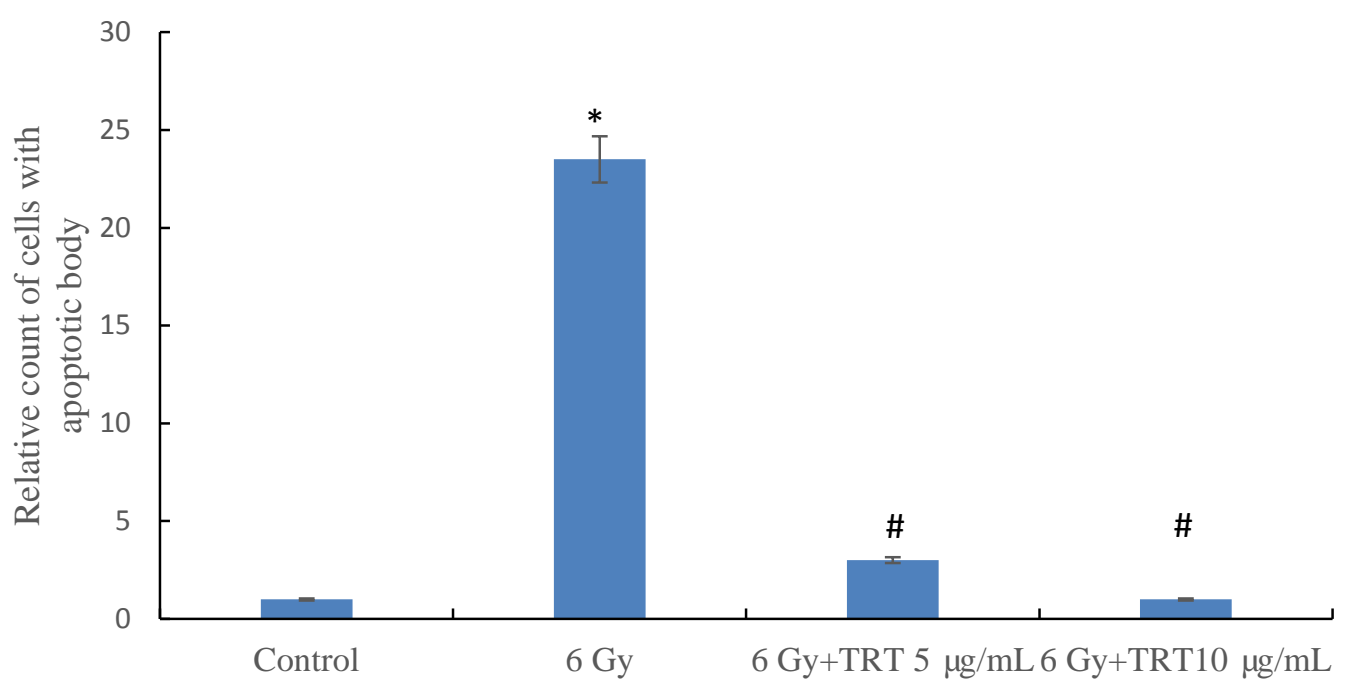

482

Fig.4

A

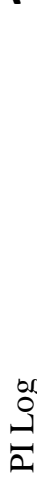

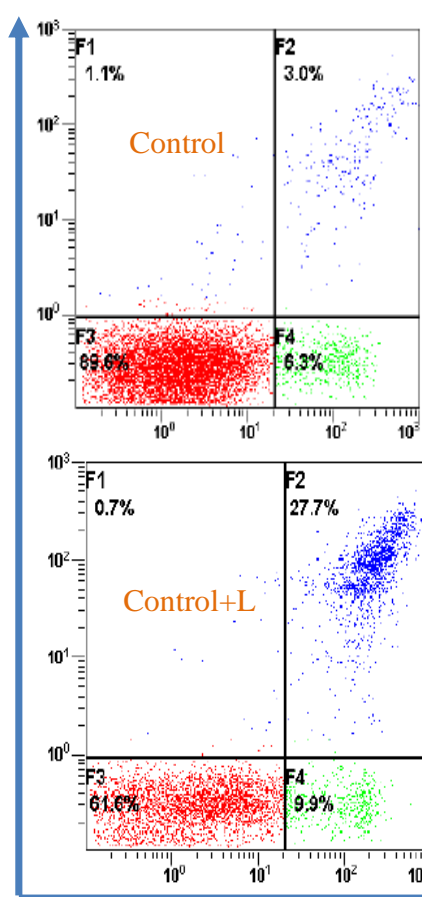

491

492

493
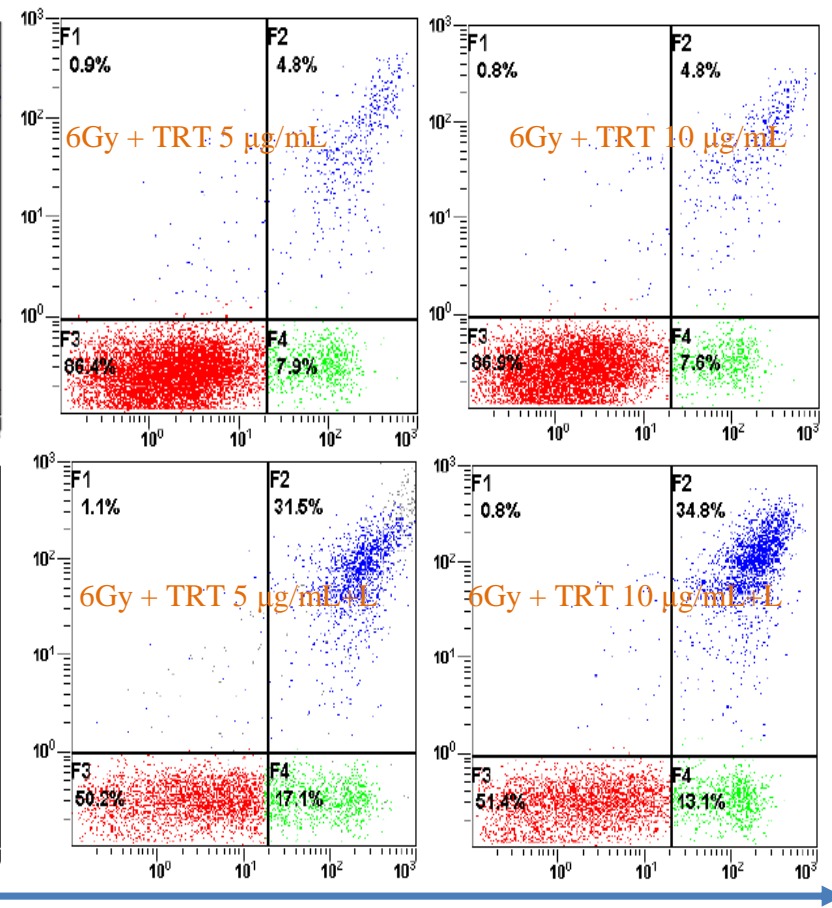

ANNEXIN-V-FITC Log L: LY294002
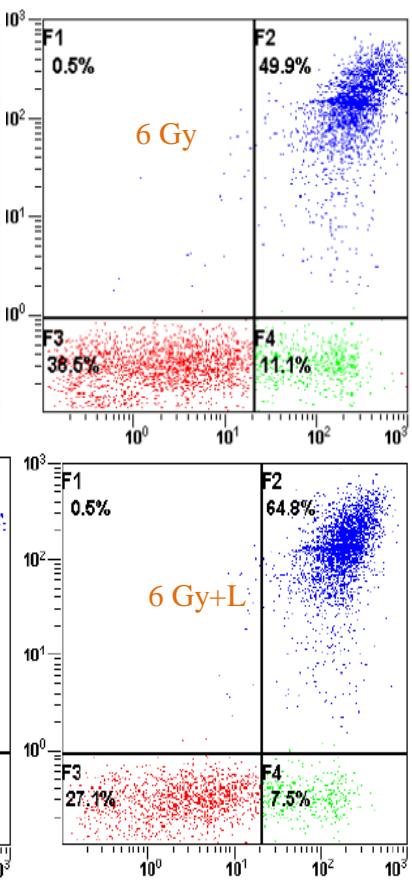


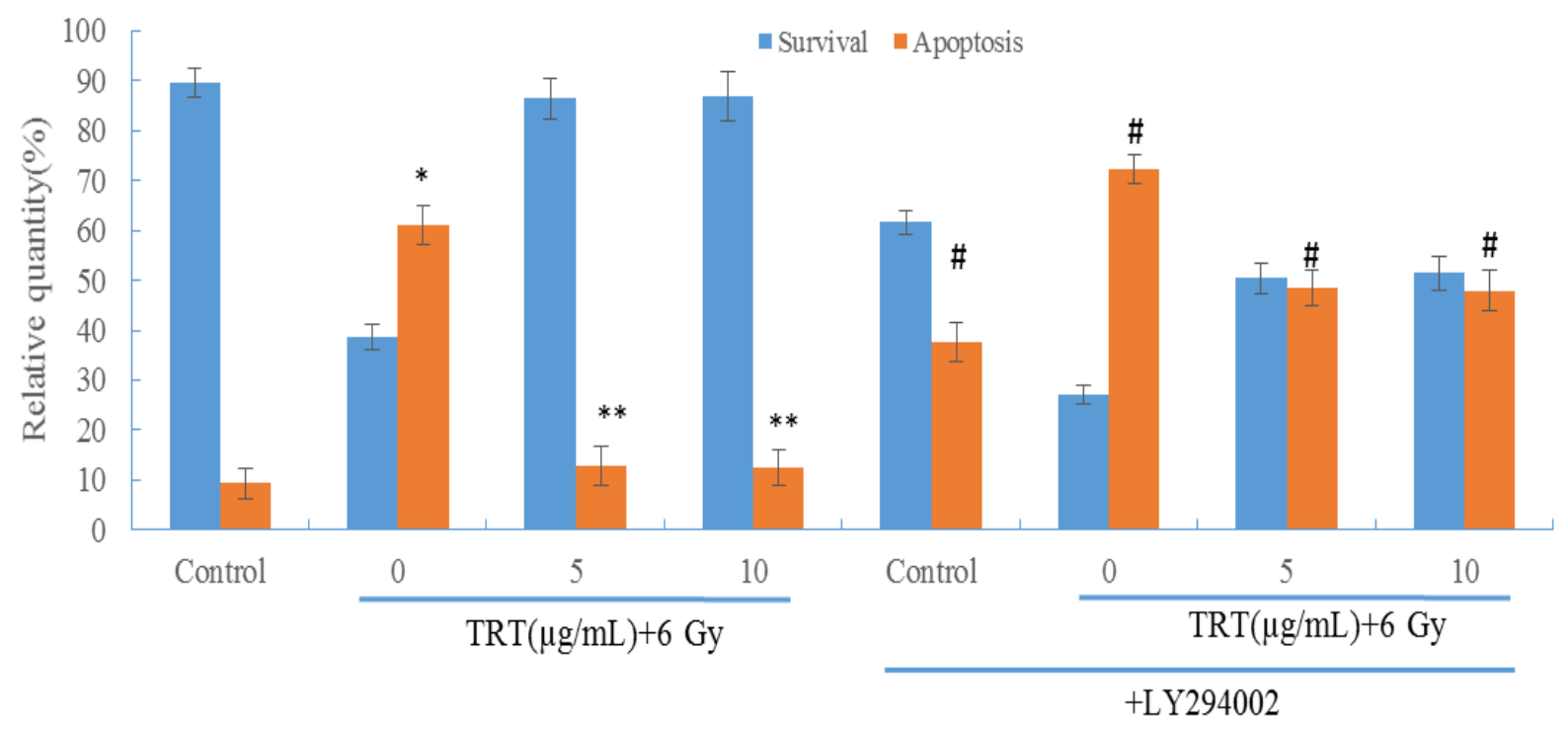

494

495
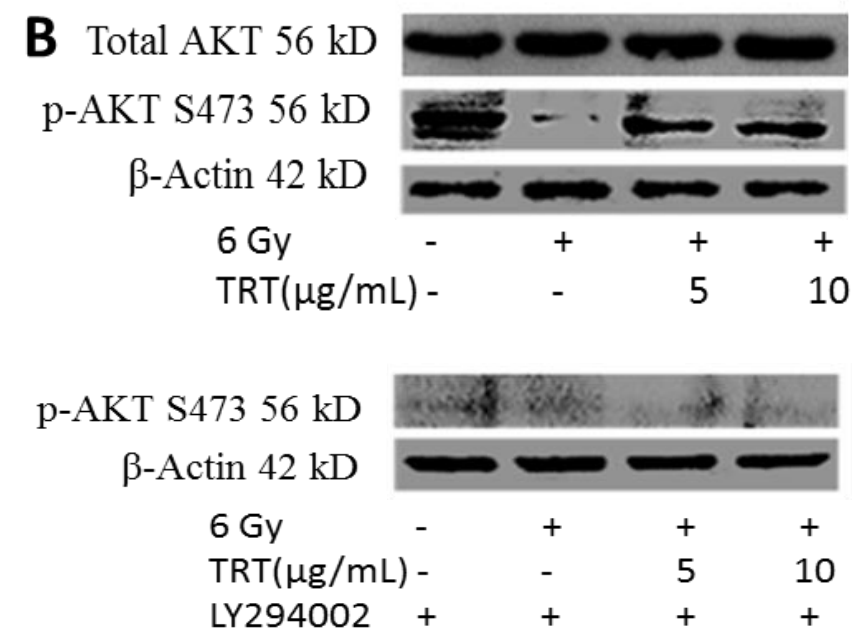

496

497

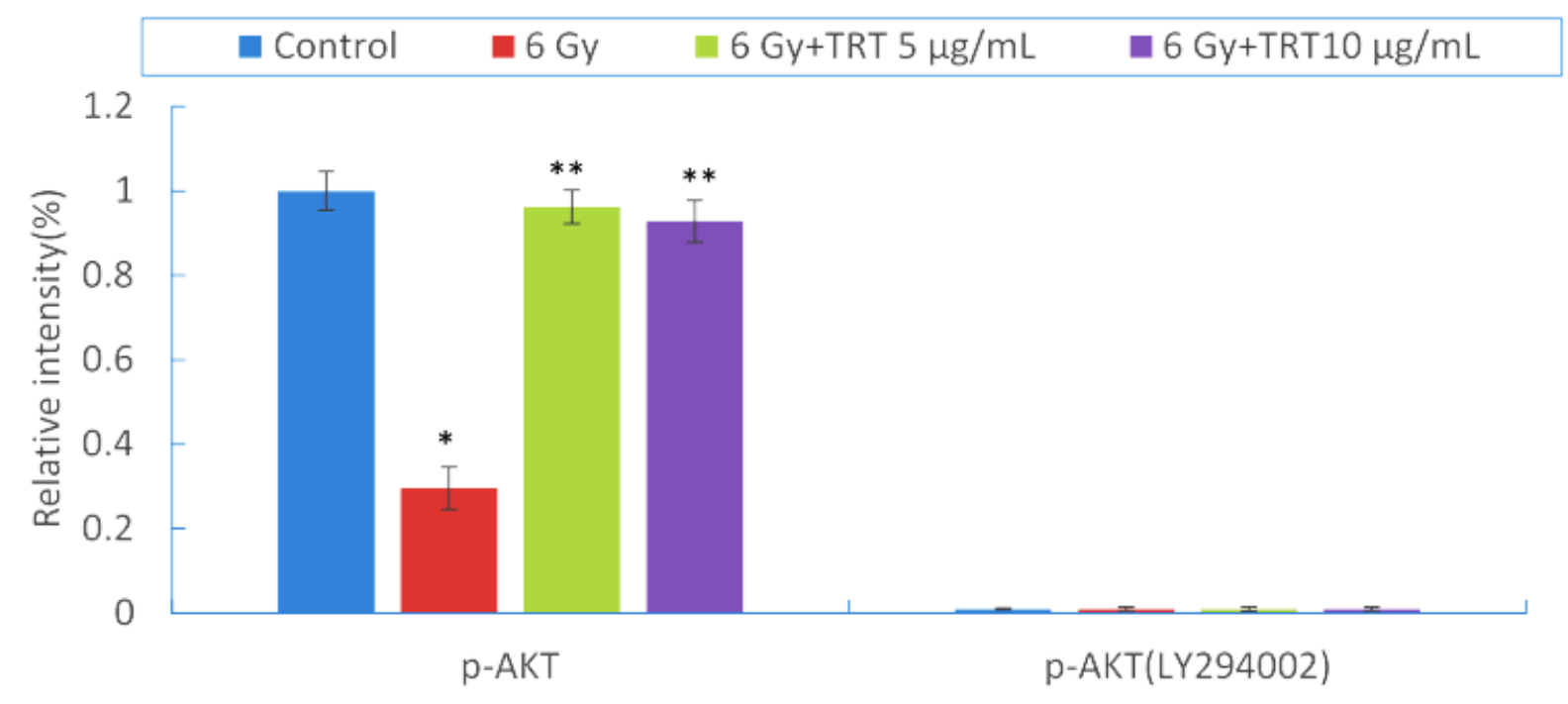




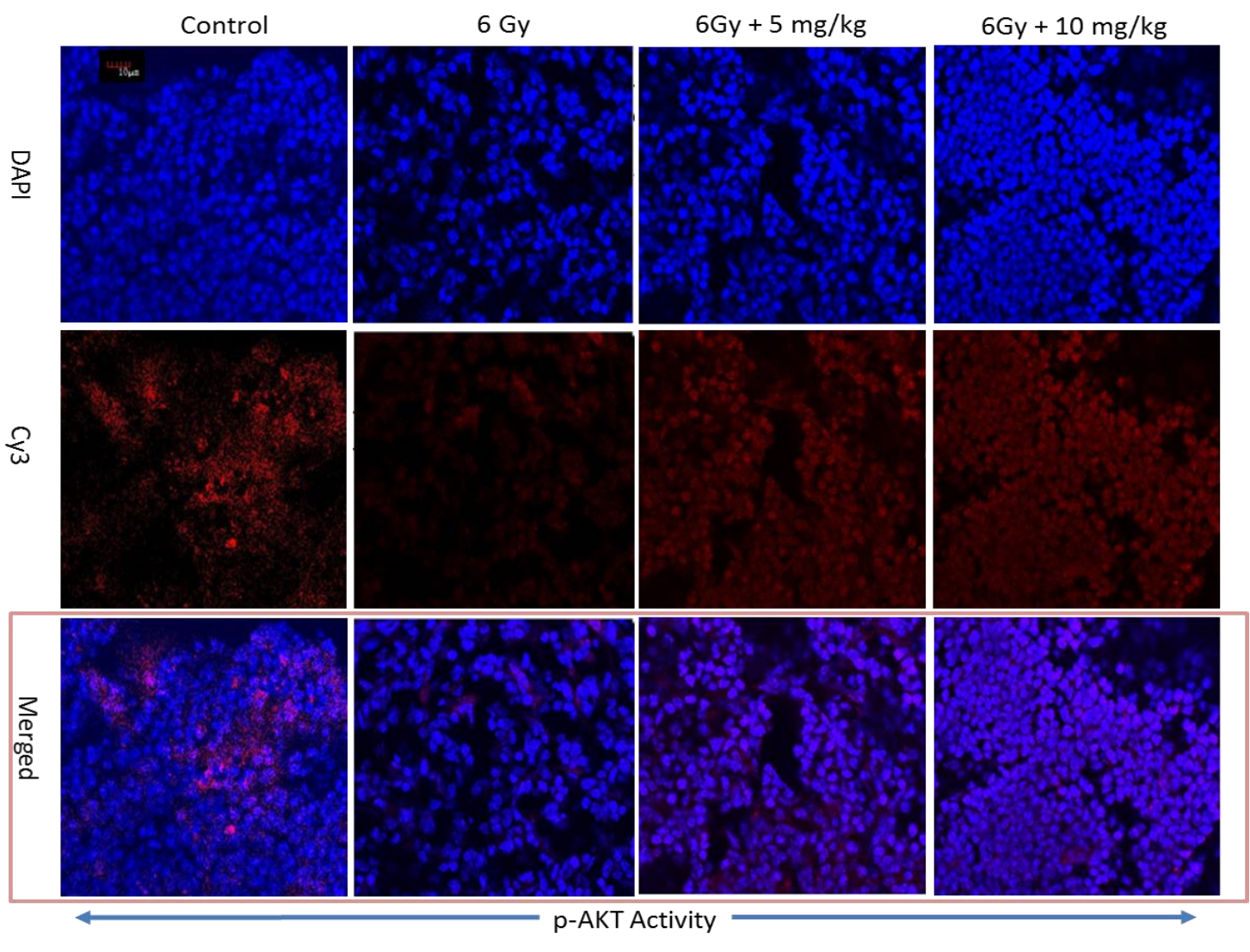

499

500

\section{C p-PTEN $54 \mathrm{kD}$}

PTEN $54 \mathrm{kD}$

$\beta$-Actin $42 \mathrm{kD}$ $6 \mathrm{~Gy}$ $\mathrm{TRT}(\mu \mathrm{g} / \mathrm{mL})$
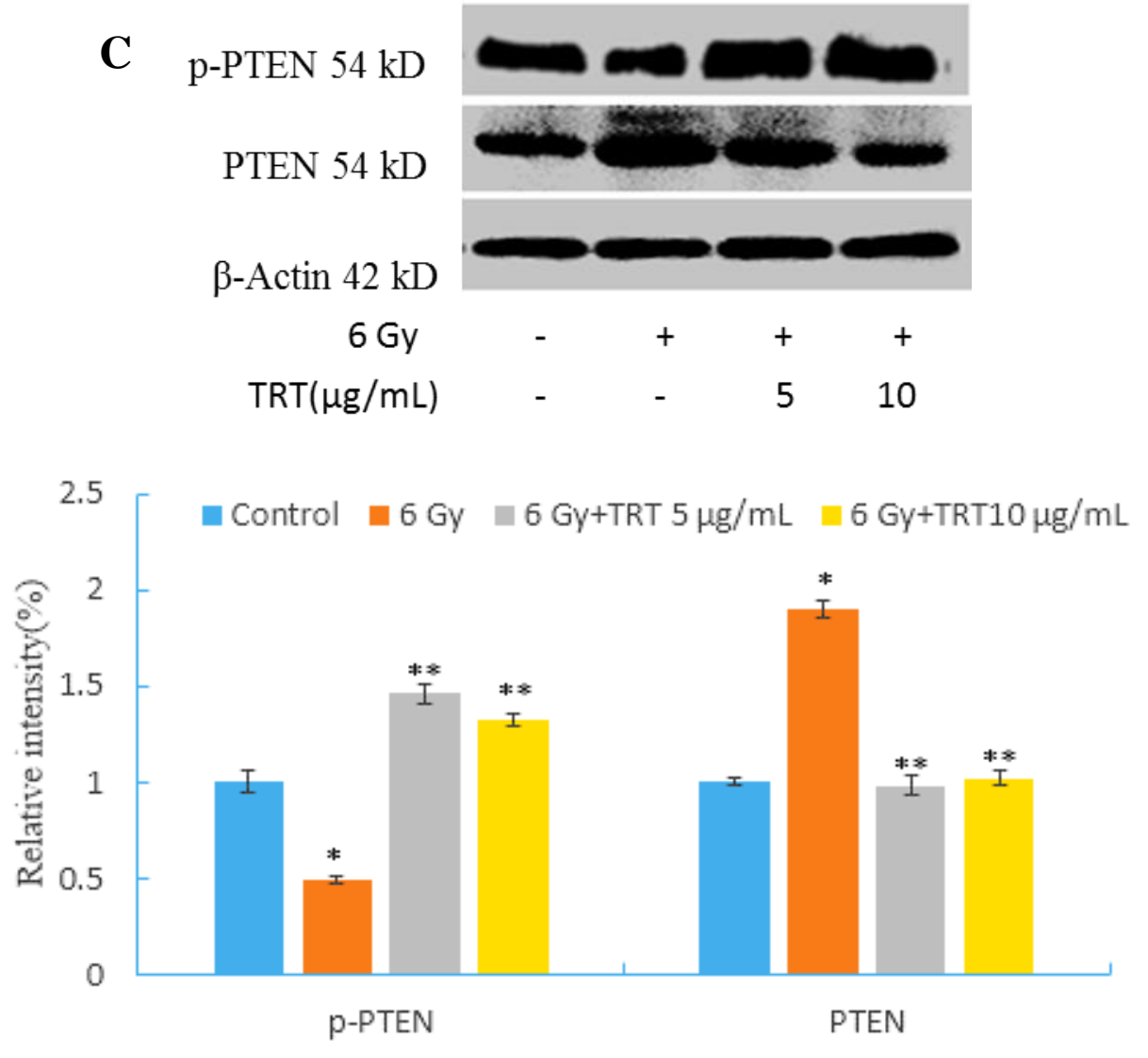
Fig.5

504

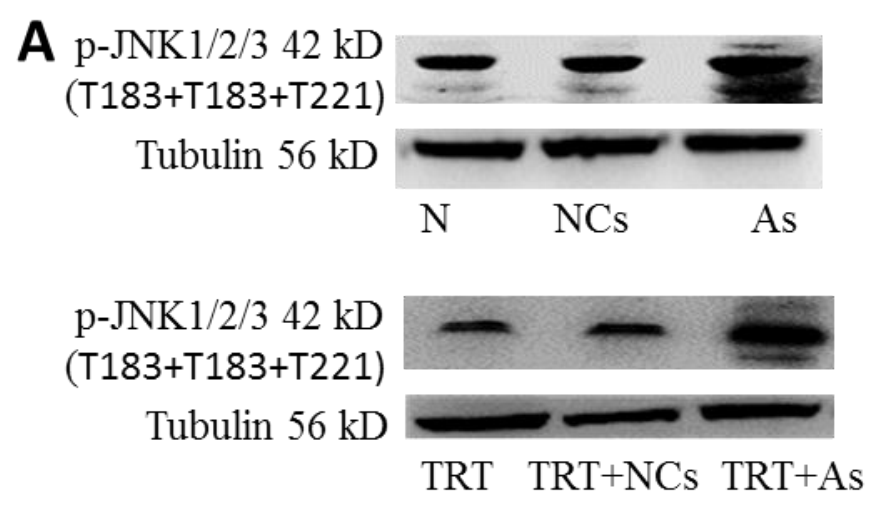

$\mathrm{N}$ : Normal

NCs: Negative control of siRNA

As: AKT siRNA

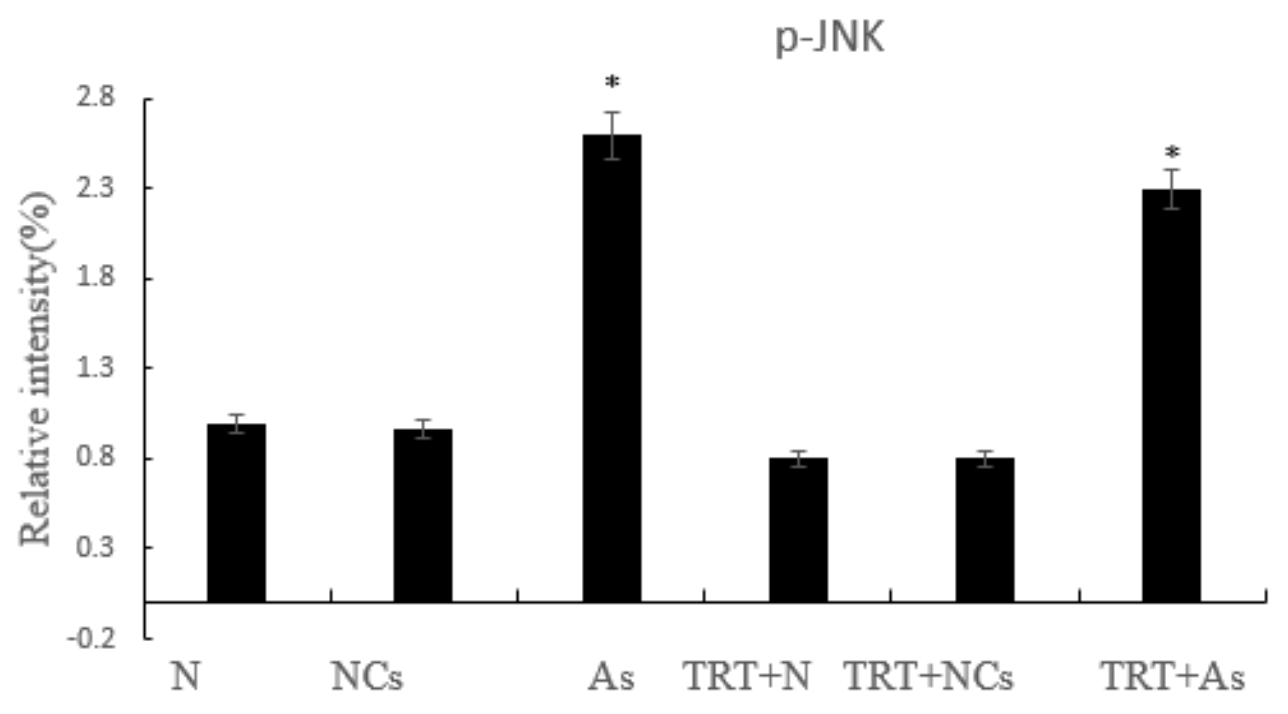

506

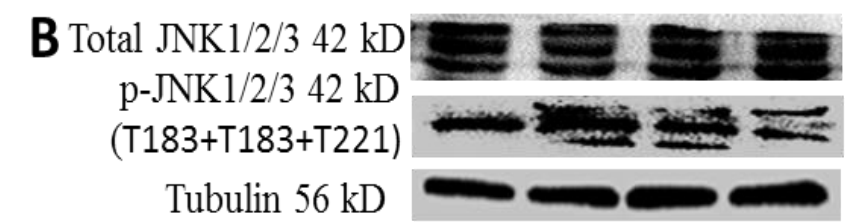

$6 \mathrm{~Gy}-\quad+\quad+\quad+$

$\mathrm{TRT}(\mu \mathrm{g} / \mathrm{mL})$ - $\quad$ - 510
p-JNK1/2/3 $42 \mathrm{kD}$

$(\mathrm{T} 183+\mathrm{T} 183+\mathrm{T} 221)$

Tubulin $56 \mathrm{kD}$

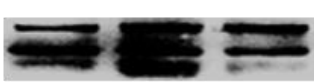

$6 \mathrm{~Gy} \quad-\quad+\quad+\quad+$ $\mathrm{TRT}(\mu \mathrm{g} / \mathrm{mL})$ - $\quad$ - 510 LY294002 + + + + 
511

512

513

514

515

516

517

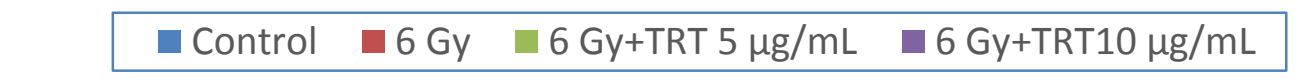

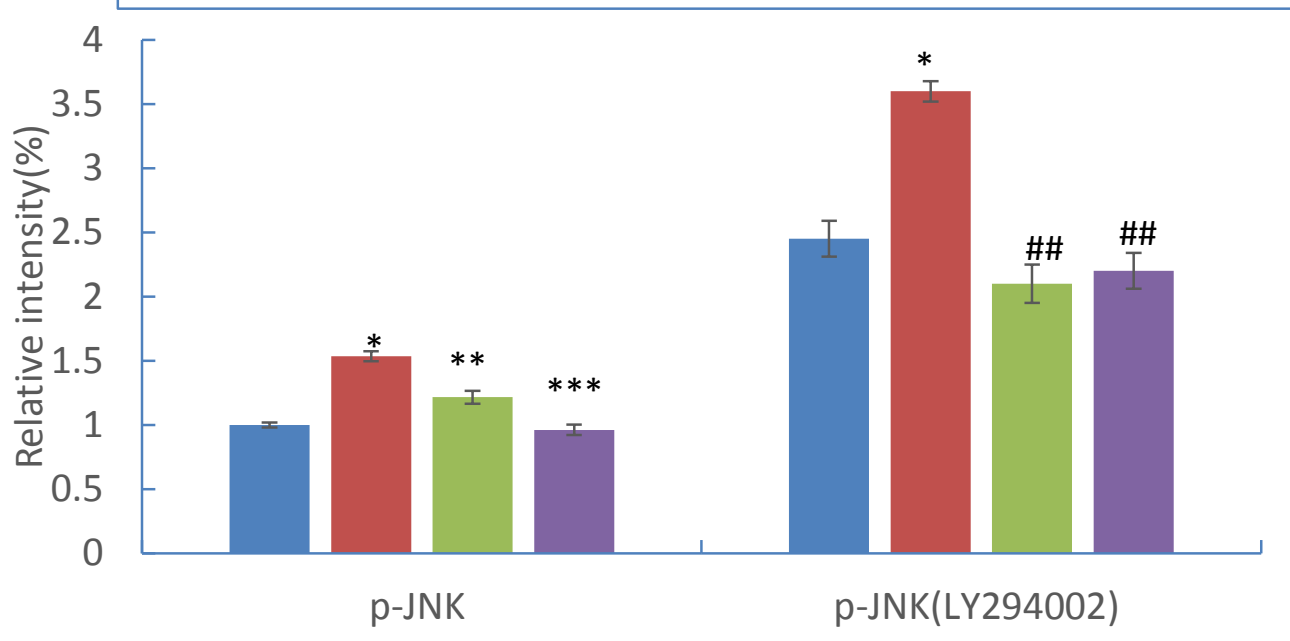

518

519

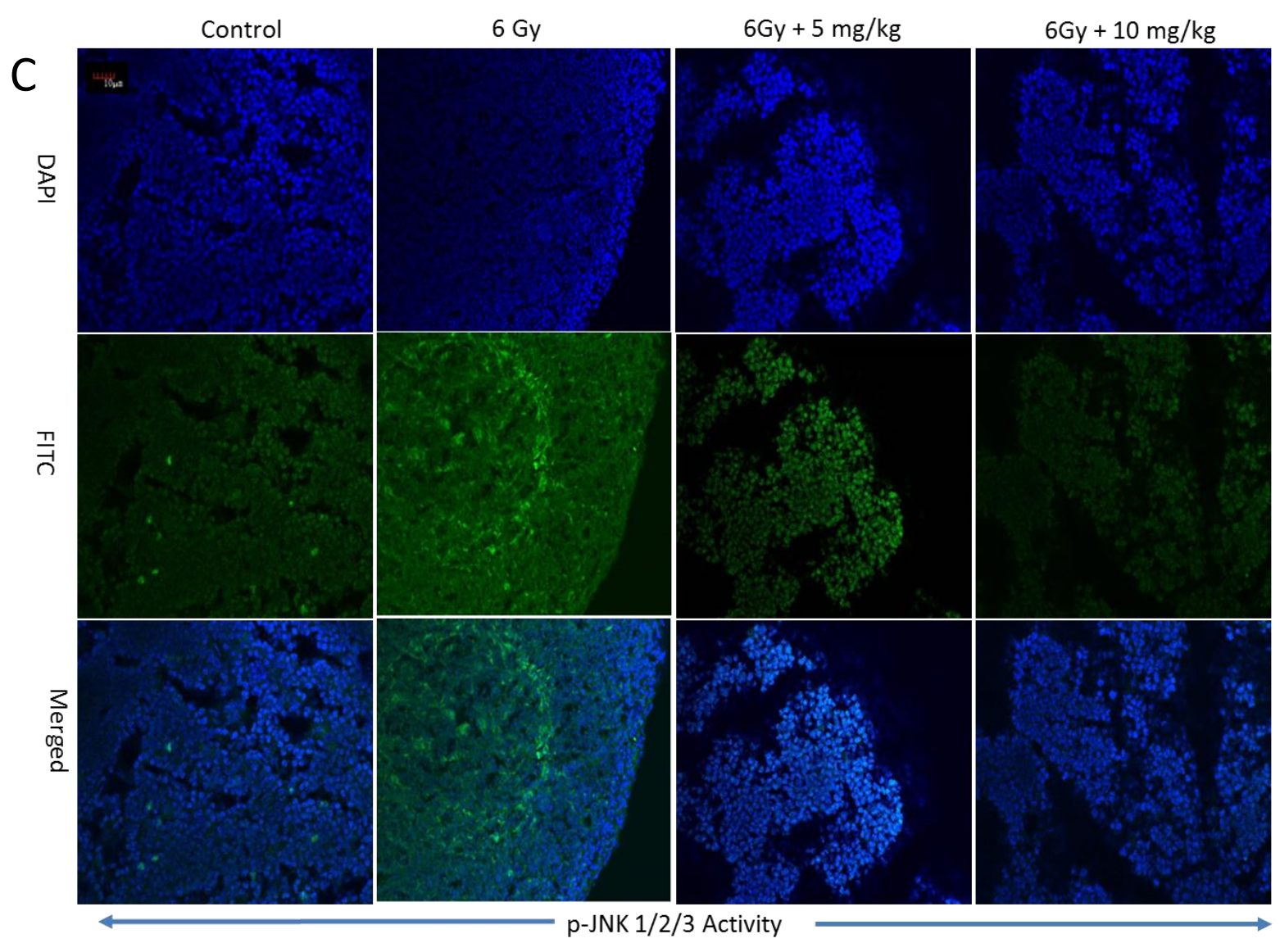

520

521 